•研究报告・

\title{
宁夏六盘山国家级自然保护区眼蝶群落多样性
}

\author{
刘学琴 贺达汉 王新谱* \\ (宁夏大学农学院, 银川 750021)
}

摘要: 蝴蝶是地球生物多样性的重要指示物种之一, 其种群动态及群落结构变化能够揭示环境改变对生态系统的 影响。六盘山国家级自然保护区生境优越, 植物区系多样, 孕育了丰富的蝶类资源。为了有效利用环境和保护蝶 类资源, 2016-2018年, 作者采用样线调查法, 对宁夏六盘山国家级自然保护区人工植被、针阔混交林、阔叶林、 灌木林 4 种生境中眼蝶亚科昆虫进行了调查, 分析了眼蝶在空间及时间上的动态变化。共记录眼蝶亚科13属19种 4,363只, 其中阿芬眼蝶 (Aphantopus hyperanthus, 961只)、亚洲白眼蝶(Melanargia asiatica, 637只)、爱珍眼蝶 (Coenonympha oedippus, 594只)分别占总数的 $22 \% 、 15 \%$ 和 $13 \%$, 为保护区优势种; 蟾眼蝶(Triphysa phryne, 17只) 仅占总数的 $0.39 \%$, 为保护区的稀有种。在空间分布上, 4 类生境中针阔混交林眼蝶物种丰富度和优势度低, 多样性 指数最高, 不同生境眼蝶群落物种丰富度指数、多样性指数、均匀度指数存在明显差异 $(P<0.05)$, 优势度指数差 异不显著。在时间动态上, 2016-2018年眼蝶个体数量呈下降趋势, 物种个体数量高峰期主要发生在 8 月, 优势种变 化明显。因此，保护宁夏六盘山国家级自然保护区蝴蝶种类多样性刻不容缓。

关键词: 眼蝶; 多样性; 种群动态; 生境

\section{Diversity of Satyrinae in the Liupanshan National Nature Reserve of Ningxia}

\author{
Xueqin Liu, Dahan He, Xinpu Wang* \\ School of Agriculture, Ningxia University, Yinchuan 750021
}

\begin{abstract}
Butterfly is one of indicator species of biodiversity, and the population dynamics and community structure of butterflies can reflect the environmental effect of Ecosystem. The Liupanshan National Nature Reserve is rich in plant resources with diversified habitats. To effectively protect and utilize environment and resources, we studied the diversity of Satyrinae in four habitat types, including artificial vegetation, shrub, broad-leaved forest, and coniferous and broad-leaved mixed forest of the Liupanshan National Nature Reserve from 2016 to 2018 by surveying transects, we discussed the spatial and temporal dynamic changes of Satyrinae. A total of 4,363 butterflies were collected, of which 19 species in 13 genera were identified. Among them, the largest numbers of individuals were Aphantopus hyperanthus (961), Melanargia asiatica (637), and Coenonympha oedippus (594), accounting for $22 \%, 15 \%$ and $13 \%$ of the assemblage respectively, all of which are dominant species in the reserve. Triphysa phryne had only 17 individuals which we regard as a rare species. We calculated and analyzed the Margalef richness index, Shannon-Wiener diversity index, Pielou evenness index, and Simpson dominance index of the four habitats. The results showed that the dominance index was lowest, but the diversity, richness, and evenness indices were highest in coniferous and broad-leaved mixed forest. The richness, diversity, and evenness indices were significantly different, while the dominance index was not for the four habitat types $(P<0.05)$. In terms of temporal dynamics, the number of Satyrinae individuals decreased from 2016 to 2018, and the peak of the number species mainly occurred in August, with significant changes in dominant species. Therefore, butterfly protection is urgent and recommended in the Liupanshan National Nature Reserve.
\end{abstract}

Key words: Satyrinae; diversity; population dynamics; habitat 
蝴蝶是无脊椎动物中个体较大、易于观察和辨 别的昆虫类群。因其对栖息地要求较高, 特别是对 温度、湿度和光照水平等环境因子的变化高度敏感, 同时也易受到森林火灾、采伐和家畜等干扰的影响, 对寄主相对专一, 成为监测与评价环境的良好生物 指示物种之一(Acharya \& Vijayan, 2015; Franzen et al, 2017; Riva et al, 2018; Crone et al, 2019)。生境植 被类型、人为干扰、生境破碎化程度、气候条件、 海拔等都对蝴蝶的生存和繁殖有着强烈的影响 (Ekroos et al, 2013; Filz et al, 2013; Allan et al, 2015; 周光益等, 2016), 通过长期的定点监测, 研究蝴蝶 种类组成变化以及与环境的相互关系, 可以为该地 区的环境质量做出评价, 从而为保护蝴蝶多样性与 恢复生态环境提供参考依据(马方舟等, 2018)。

眼蝶亚科录属昆虫纲鳞翅目风蝶总科蛱蝶科, 分布广泛(周尧, 1998)。同时, 眼蝶也是蝶类中种类 最丰富、数量最多的类群，对环境变化十分敏感， 是许多研究领域(如生态学、功能基因组学等)的重 要研究对象。全世界共有眼蝶2,500种(Peña et al, 2011), 周尧1994年首次记录了中国眼蝶212种(含亚 种), 2001年又增加了29种(含亚种和新记录种)(周尧, 1994; 周尧等, 2001), 寿建新(2006)编著的《世界蝴 蝶分类名录》里记录了中国眼蝶395种。此后Zhai 和Zhang (2011)、胡华林等(2014)、胡金贵等(2016) 又发现中国眼蝶新种及新记录种并发表。眼蝶多以 禾本科、莎草科植物为寄主, 其分布和数量都受植 物区系的影响。近些年来, 我国许多地区已开展了 自然保护区蝶类多样性研究(房丽君和张雅林, 2010; 邓合黎等, 2012; 张金等, 2013; 旦智措等, 2018; 马 方舟等, 2018), 试图探讨自然保护区自然环境变化 与蝶类的关系以及对环境监测的意义。

六盘山国家级自然保护区(以下简称六盘山保 护区)位于宁夏南部, 镶嵌于秦岭、祁连山两大山脉 之间, 地理位置特殊, 是西北地区森林生态系统类 型的自然保护区和重要的水源涵养地(任国栋, 2010), 但目前对该地的蝶类多样性研究报道甚少, 国内只有房丽君和张雅林(2010)对六盘山的蝶类区 系组成进行了调查, 共记录5科68属130种, 其中眼 蝶12属24种。本文作者自2016年开始对六盘山保护 区蝴蝶进行监测记录, 发现眼蝶亚科在种类和数量 上最多, 为保护区优势科, 鉴于眼蝶对环境的极强
敏感性以及与植物的相互依存关系，本文对眼蝶的 种类及种群动态进行研究, 以期为六盘山蝶类的合 理保护和环境质量的监测提供参考依据。

\section{研究区域概况}

六盘山保护区地处 $35^{\circ} 15^{\prime}-35^{\circ} 41^{\prime} \mathrm{N}, 106^{\circ} 09^{\prime}-$ $106^{\circ} 31^{\prime} \mathrm{E}$, 位于宁夏南部, 黄土高原西部, 横贯陕 甘宁三省区, 总面积 6.78 万ha, 南北长200余公里, 平均海拔2,200 m, 主峰米缸山高2,942 $\mathrm{m}$, 是宁夏 三大次生林区之一(六盘山自然保护区科学考察编 辑委员会, 1988)。该地区具有明显的大陆性和海洋 季风边缘气候特点, 无霜期 $90-130 \mathrm{~d}$, 年均温 $5-6^{\circ} \mathrm{C}$, 年降水量600-700 mm, 降雨充沛, 水资源十分丰 富。土壤类型以山地灰褐土为主, 还包括山地棕壤 和山地草甸土。植被类型分为温带落叶阔叶林、针 阔混交林、山地灌丛草原、山地草甸草原和亚高山 草甸等7种类型; 主要树种有华北落叶松 (Larix principis-rupprechtii)、油松(Pinus tabuliformis)、华 山松(P. armandii)、山杨(Populus davidiana)、白桦 (Betula platyphylla)、辽东柇(Quercus liaotungensis)、 槭树(Acer miyabei)和山柳(Salix pseudotangii)等; 灌 木主要有山楂(Crataegus pinnatifida)、忍 (Lonicera japonica)和山桃(Amygdalus davidiana), 周边还有 大量农用耕地, 主要种植玉米(Zea mays)、苜宿 (Medicago spp.)、马铃薯(Solanum tuberosum)、人工 栽植的青海云杉(Picea crassifolia)和油松树苗等。

\section{研究方法}

\section{1 蝶类调查}

根据六盘山保护区的植被特征和干扰类型，选 择针阔混交林、阔叶林、灌木林、人工植被 4 类不 同的生境, 同类生境分别在保护区内外设置样线, 样线间距大于 $2 \mathrm{~km}$, 共10条样线(表1, 图1)。每条样 线长 $2 \mathrm{~km}$, 按 $400 \mathrm{~m}$ 分段统计眼蝶种类和数量。

调查于 2016-2018年每年的5-9月进行，依据 《生物多样性观测技术导则: 蝴蝶》(HJ710.9-2014), 选择晴朗的天气, 于蝶类活动频繁的9:00-17:00开 展调查。观测时, 调查者沿样线以 $1.0-1.5 \mathrm{~km} / \mathrm{h}$ 的速 度匀速前行, 记录样线左右各 $2.5 \mathrm{~m}$ 、上方 $5 \mathrm{~m}$ 、前 方 $5 \mathrm{~m}$ 范围内见到的所有眼蝶亚科的种类和数量, 不重复计数同一只和身后的个体, 对于不能确定的 
表1 六盘山国家级自然保护区眼蝶调查样线概况

Table 1 Characteristic of butterfly sampling transects in the Liupanshan National Nature Reserve

\begin{tabular}{|c|c|c|c|c|c|c|}
\hline $\begin{array}{l}\text { 样线 } \\
\text { Transect }\end{array}$ & $\begin{array}{l}\text { 位置 } \\
\text { Location }\end{array}$ & $\begin{array}{l}\text { 海拔范围 } \\
\text { Range of elevation (m) }\end{array}$ & $\begin{array}{l}\text { 经纬度 } \\
\text { Longitude and latitude }\end{array}$ & $\begin{array}{l}\text { 生境类型 } \\
\text { Habitat type }\end{array}$ & $\begin{array}{l}\text { 植被特征 } \\
\text { Vegetation characters }\end{array}$ & $\begin{array}{l}\text { 干扰程度 } \\
\text { Disturbance }\end{array}$ \\
\hline $\mathrm{T} 1$ & $\begin{array}{l}\text { 冶家村 } \\
\text { Yejiacun }\end{array}$ & $1,792-1,842$ & $\begin{array}{l}35^{\circ} 24^{\prime} 49^{\prime \prime} \mathrm{N} \\
106^{\circ} 23^{\prime} 02^{\prime \prime} \mathrm{E}\end{array}$ & $\begin{array}{l}\text { 人工植被 } \\
\text { Artificial vegetation }\end{array}$ & $\begin{array}{l}\text { 马铃薯、苜宿等 } \\
\text { Solanum tuberosum, Medicago } \\
\text { spp. etc. }\end{array}$ & $\begin{array}{l}\text { 弱 } \\
\text { Weak }\end{array}$ \\
\hline $\mathrm{T} 2$ & $\begin{array}{l}\text { 龙潭林场 } \\
\text { Longtan forest } \\
\text { farm }\end{array}$ & $1,860-1,894$ & $\begin{array}{l}35^{\circ} 20^{\prime} 03^{\prime \prime} \mathrm{N} \\
106^{\circ} 21^{\prime} 39^{\prime \prime} \mathrm{E}\end{array}$ & $\begin{array}{l}\text { 针阔混交林 } \\
\text { Coniferous and } \\
\text { broad-leaved mixed } \\
\text { forest }\end{array}$ & $\begin{array}{l}\text { 华北落叶松林、油松林为主 } \\
\text { Larix principis-rupprechtii } \\
\text { forest and Pinus tabuliformis } \\
\text { forest }\end{array}$ & $\begin{array}{l}\text { 弱 } \\
\text { Weak }\end{array}$ \\
\hline T3 & $\begin{array}{l}\text { 龙潭水库 } \\
\text { Longtan } \\
\text { reservoir }\end{array}$ & $1,850-1,873$ & $\begin{array}{l}35^{\circ} 21^{\prime} 00^{\prime \prime} \mathrm{N} \\
106^{\circ} 18^{\prime} 43^{\prime \prime} \mathrm{E}\end{array}$ & $\begin{array}{l}\text { 人工植被 } \\
\text { Artificial vegetation }\end{array}$ & $\begin{array}{l}\text { 人工栽植槐树、草坪等 } \\
\text { Artificial plantation of Sophora } \\
\text { japonica, lawns etc. }\end{array}$ & $\begin{array}{l}\text { 弱 } \\
\text { Weak }\end{array}$ \\
\hline $\mathrm{T} 4$ & $\begin{array}{l}\text { 小南川 } \\
\text { Xiaonanchuan }\end{array}$ & $1,965-2,000$ & $\begin{array}{l}35^{\circ} 23^{\prime} 51^{\prime \prime} \mathrm{N} \\
106^{\circ} 21^{\prime} 19^{\prime \prime} \mathrm{E}\end{array}$ & $\begin{array}{l}\text { 阔叶林 } \\
\text { Broad-leaved forest }\end{array}$ & $\begin{array}{l}\text { 白桦、辽东栋和山柳等 } \\
\text { Betula platyphylla, Quercus } \\
\text { liaotungensis, Salix } \\
\text { pseudotangii etc. }\end{array}$ & $\begin{array}{l}\text { 强 } \\
\text { Strong }\end{array}$ \\
\hline T5 & $\begin{array}{l}\text { 二龙河 } \\
\text { Erlonghe }\end{array}$ & $2,068-2,213$ & $\begin{array}{l}35^{\circ} 23^{\prime} 25^{\prime \prime} \mathrm{N} \\
106^{\circ} 22^{\prime} 15^{\prime \prime} \mathrm{E}\end{array}$ & $\begin{array}{l}\text { 针阔混交林 } \\
\text { Coniferous and broad- } \\
\text { leaved mixed forest }\end{array}$ & $\begin{array}{l}\text { 华北落叶松林、油松林为主 } \\
\text { Larix principis-rupprechtii } \\
\text { forest and Pinus tabuliformis } \\
\text { forest }\end{array}$ & $\begin{array}{l}\text { 无 } \\
\text { None }\end{array}$ \\
\hline T6 & $\begin{array}{l}\text { 红家峡1 } \\
\text { Hongjiaxia1 }\end{array}$ & 1,993-2,099 & $\begin{array}{l}35^{\circ} 35^{\prime} 51^{\prime \prime} \mathrm{N} \\
106^{\circ} 14^{\prime} 17^{\prime \prime} \mathrm{E}\end{array}$ & $\begin{array}{l}\text { 针阔混交林 } \\
\text { Coniferous and broad- } \\
\text { leaved mixed forest }\end{array}$ & $\begin{array}{l}\text { 华北落叶松林、油松林为主 } \\
\text { Larix principis-rupprechtii } \\
\text { forest and Pinus tabuliformis } \\
\text { forest }\end{array}$ & $\begin{array}{l}\text { 无 } \\
\text { None }\end{array}$ \\
\hline $\mathrm{T} 7$ & $\begin{array}{l}\text { 红家峡2 } \\
\text { Hongjiaxia2 }\end{array}$ & $2,202-2,283$ & $\begin{array}{l}35^{\circ} 27^{\prime} 10^{\prime \prime} \mathrm{N} \\
106^{\circ} 17^{\prime} 59^{\prime \prime} \mathrm{E}\end{array}$ & $\begin{array}{l}\text { 灌木林 } \\
\text { Shrub }\end{array}$ & $\begin{array}{l}\text { 灌木 } \\
\text { Shrub }\end{array}$ & $\begin{array}{l}\text { 弱 } \\
\text { Weak }\end{array}$ \\
\hline T8 & $\begin{array}{l}\text { 东山坡 } \\
\text { Dongshanpo }\end{array}$ & $2,203-2,440$ & $\begin{array}{l}35^{\circ} 27^{\prime} 13^{\prime \prime} \mathrm{N} \\
106^{\circ} 15^{\prime} 53^{\prime \prime} \mathrm{E}\end{array}$ & $\begin{array}{l}\text { 针阔混交林 } \\
\text { Coniferous and broad- } \\
\text { leaved mixed forest }\end{array}$ & $\begin{array}{l}\text { 华北落叶松林、油松林为主 } \\
\text { Larix principis-rupprechtii } \\
\text { forest and Pinus tabuliformis } \\
\text { forest }\end{array}$ & $\begin{array}{l}\text { 无 } \\
\text { None }\end{array}$ \\
\hline T9 & $\begin{array}{l}\text { 大南沟 } \\
\text { Danangou }\end{array}$ & $2,078-2,270$ & $\begin{array}{l}35^{\circ} 32^{\prime} 09^{\prime \prime} \mathrm{N} \\
106^{\circ} 14^{\prime} 29^{\prime \prime} \mathrm{E}\end{array}$ & $\begin{array}{l}\text { 针阔混交林 } \\
\text { Coniferous and broad- } \\
\text { leaved mixed forest }\end{array}$ & $\begin{array}{l}\text { 华北落叶松林、油松林为主 } \\
\text { Larix principis-rupprechtii } \\
\text { forest and Pinus tabuliformis } \\
\text { forest }\end{array}$ & $\begin{array}{l}\text { 无 } \\
\text { None }\end{array}$ \\
\hline $\mathrm{T} 10$ & $\begin{array}{l}\text { 草沟 } \\
\text { Caogou }\end{array}$ & $2,204-2,286$ & $\begin{array}{l}35^{\circ} 29^{\prime} 27^{\prime \prime} \mathrm{N} \\
106^{\circ} 16^{\prime} 00^{\prime \prime} \mathrm{E}\end{array}$ & $\begin{array}{l}\text { 针阔混交林 } \\
\text { Coniferous and broad- } \\
\text { leaved mixed forest }\end{array}$ & $\begin{array}{l}\text { 华北落叶松林、油松林为主 } \\
\text { Larix principis-rupprechtii } \\
\text { forest and Pinus tabuliformis } \\
\text { forest }\end{array}$ & $\begin{array}{l}\text { 无 } \\
\text { None }\end{array}$ \\
\hline
\end{tabular}

种类，网捕后进行鉴定，确定种类后原地释放。当 场不能确定的种类进行少量网捕并编号，带回实验 室鉴定、统计记录。标本的鉴定依据《中国蝴蝶分 类与鉴定》(周尧, 1999)、《中国蝴蝶原色图鉴》(周 尧, 1998)、《世界蝴蝶分类名录》(寿建新, 2006)。

\section{2 优势属种的划分}

定义分布在 4 个生境内、个体数在 200 只以上的 种为优势种; 分布在3-4个生境、个体数在99只以下 的种为常见种; 分布在 1 个生境内, 个体数在 6 只以 上99只以下的种为稀有种; 分布在 1 个生境、个体数 在5只以下的种为罕见种(杨萍等, 2002)。

\section{3 群落多样性分析}

采用Margalef丰富度指数 $(D$, 马克平和刘玉明, 1994)、Shannon-Wiener多样性指数 $\left(H^{\prime}\right.$, Margalef, 1967)、Pielou均匀度指数 (J, Whittaker, 1972)、 Simpson优势度指数 $(C$, Pielou, 1975) 对群落多样性 进行分析，计算公式如下:

$$
\begin{aligned}
& D=(S-1) / \ln N \\
& H^{\prime}=-\sum_{\mathrm{i}=1}^{S} P_{\mathrm{i}} \ln P_{\mathrm{i}} \\
& J=H^{\prime} / \ln S
\end{aligned}
$$



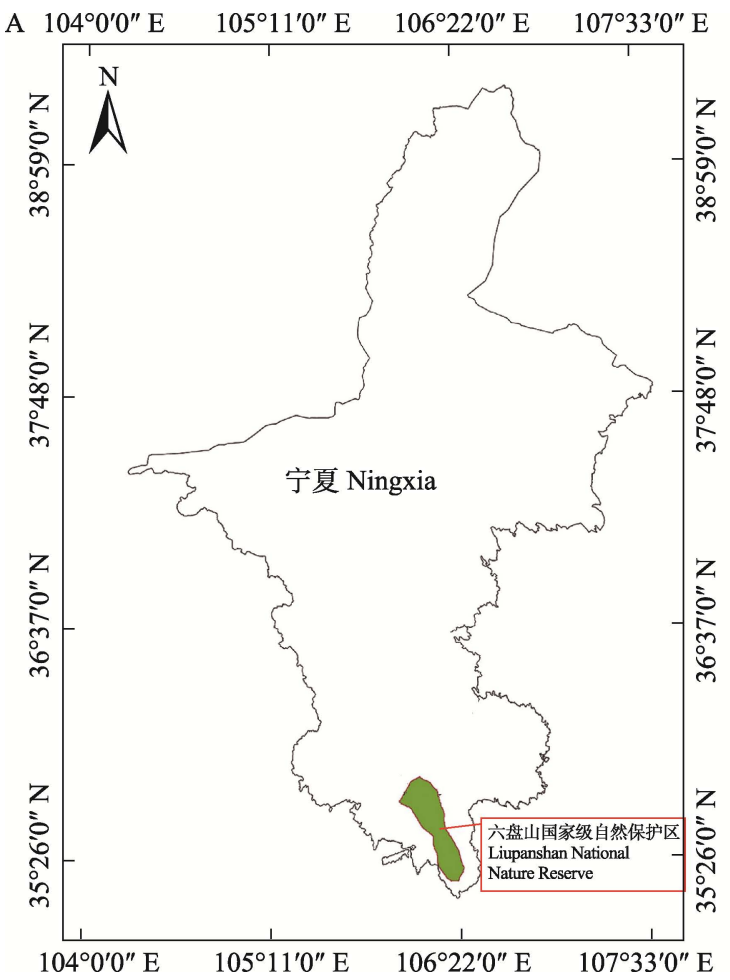

B

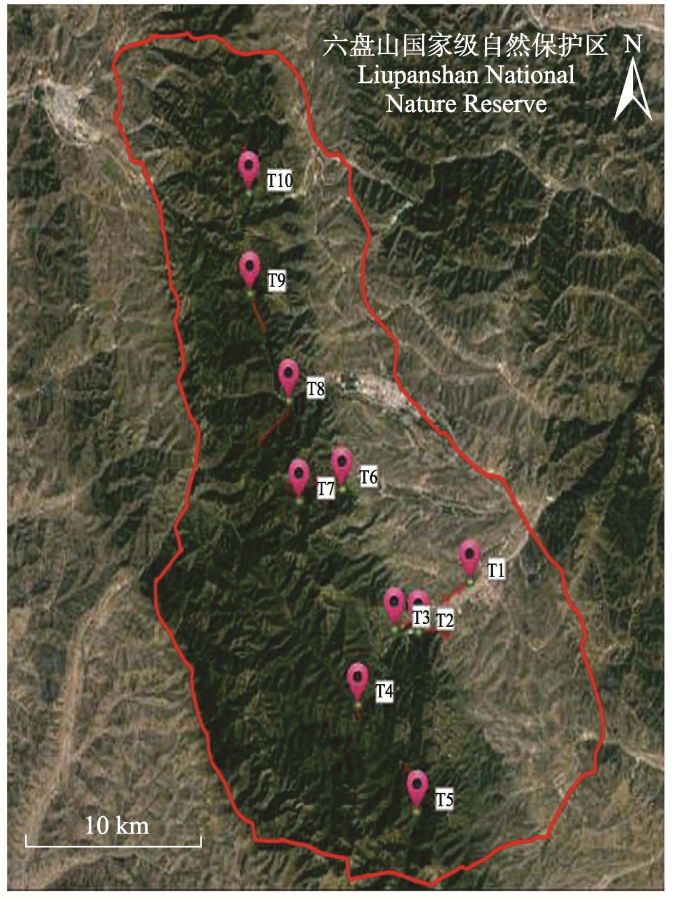

图1 六盘山国家级自然保护区眼蝶调查样线图

Fig. 1 The location of sampling transects of Satyrinae in the Liupanshan National Nature Reserve

$$
C=\frac{N_{\mathrm{i}}\left(N_{\mathrm{i}}-1\right)}{N(N-1)}
$$

式中, $S$ 为物种数, $N$ 为所有物种个体数之和。 $P_{\mathrm{i}}=$ $N_{\mathrm{i}} / N$, 是第 $\mathrm{i}$ 种的个体数占总个体数的比例, $N_{\mathrm{i}}$ 是第 $\mathrm{i}$ 种的个体数。以上指数通过RStudio软件计算并绘制 箱线图。

采用Jaccard相似性系数分析群落间的相似性 (Jaccard, 1900), 公式如下:

$$
I=c /(a+b-c)
$$

式中, $a$ 为 $\mathrm{A}$ 生境物种数, $b$ 为 $\mathrm{B}$ 生境物种数, $c$ 为 $\mathrm{A} 、 \mathrm{~B}$ 两生境共有的物种数。当 $I$ 为 $0-0.25$ 时, 为极不相似; $I$ 为 $0.25-0.50$ 时, 为中等不相似; $I$ 为 $0.50-0.75$ 时, 为 中等相似; $I$ 为 $0.75-1.00$ 时, 为极相似(陈振宁和曾 阳, 2001)。

\section{3 结果}

\section{1 眼蝶群落组成}

\subsection{1 眼蝶群落组成及数量}

2016-2018年共调查记录眼蝶4,363只, 隶属13 属19种(表2), 其中, 珍眼蝶属(Coenonympha)和黛 眼蝶属 (Lethe) 各3种, 分别占总种数的 $15.79 \%$; 云
眼蝶属 (Hyponephele) 和警眼蝶属 (Ypthima) 各 2 种, 分别占总种数的 $10.53 \%$; 阿芬眼蝶属(Aphantopus)、 藏眼蝶属(Tatinga)、蟾眼蝶属(Triphysa)、红眼蝶属 (Erebia)、黄斑荫眼蝶属(Neope)、黄环链眼蝶属 (Lopinga)、仁眼蝶属(Eumenis)、蛇眼蝶属(Minois) 和亚洲白眼蝶属(Melanargia)只有1种, 共占总种数 的 $31.57 \%$ 。

从个体数量来看, 六盘山保护区3年观测记录 阿芬眼蝶(Aphantopus hyperanthus)、亚洲白眼蝶 (Melanargia asiatica)和爱珍眼蝶(Coenonympha oedippus) 个体数量相对较多, 分别为 961 只、637只、 594 只, 占个体总数的 $22 \% 、 15 \%$ 和 $13 \%$, 为保护区 主要优势种。牧女珍眼蝶(Coenonympha amaryllis)、 藏眼蝶(Tatinga thibetana)、黑带黛眼蝶(Lethe nigrifascia)、红眼蝶(Erebia alcmena)、黄斑荫眼蝶 (Neope pulaha)、黄环链眼蝶(Lopinga achine)、居间 云眼蝶 (Hyponephele interposita)、乱云賋眼蝶 (Ypthima megalomma)、箅眼蝶 (Y. balda)、仁眼蝶 (Eumenis autonoe)、蛇眼蝶(Minois dryas)、油庆珍 眼蝶(Coenonympha glycerion)、苔娜黛眼蝶(Lethe diana)、云南黛眼蝶(L.yunnana)、西方云眼 
表2 2016-2018年六盘山国家级自然保护区不同生境眼蝶的种类与数量

Table 2 Species and individual numbers of Satyrinae recorded in different habitat types of the Liupanshan National Nature Reserve from 2016 to 2018

\begin{tabular}{|c|c|c|c|c|c|c|c|c|c|c|c|c|c|c|c|c|}
\hline \multirow[b]{2}{*}{ 种类 Species } & \multicolumn{5}{|c|}{2016} & \multicolumn{5}{|c|}{2017} & \multicolumn{6}{|c|}{2018} \\
\hline & AV & CB & $\mathrm{SH}$ & $\mathrm{BF}$ & $\begin{array}{l}\text { 小计 } \\
\text { Sub- } \\
\text { total } \\
\end{array}$ & $\mathrm{AV}$ & CB & $\mathrm{SH}$ & $\mathrm{BF}$ & $\begin{array}{l}\text { 小计 } \\
\text { Sub- } \\
\text { total }\end{array}$ & AV & CB & $\mathrm{SH}$ & $\mathrm{BF}$ & $\begin{array}{l}\text { 小计 } \\
\text { Sub- } \\
\text { total }\end{array}$ & $\begin{array}{l}\text { 总计 } \\
\text { Total }\end{array}$ \\
\hline \multicolumn{17}{|l|}{ 阿芬眼蝶属 Aphantopus } \\
\hline 阿芬眼蝶 A. hyperanthus & 28 & 530 & 34 & 13 & 605 & 6 & 203 & 15 & 16 & 240 & 0 & 98 & 10 & 8 & 116 & 961 \\
\hline \multicolumn{17}{|l|}{ 珍眼蝶属 Coenonympha } \\
\hline 爱珍眼蝶 C. oedippus & 11 & 12 & 0 & 0 & 23 & 43 & 269 & 2 & 15 & 329 & 33 & 192 & 3 & 14 & 242 & 594 \\
\hline 牧女珍眼蝶 C. amaryllis & 2 & 8 & 0 & 0 & 10 & 21 & 9 & 0 & 0 & 30 & 7 & 4 & 1 & 1 & 13 & 53 \\
\hline 油庆珍眼蝶 C. glycerion & 62 & 238 & 7 & 5 & 312 & 0 & 53 & 0 & 0 & 53 & 0 & 1 & 0 & 0 & 1 & 366 \\
\hline \multicolumn{17}{|l|}{ 藏眼蝶属 Tatinga } \\
\hline 藏眼蝶 T. thibetana & 0 & 28 & 1 & 1 & 30 & 0 & 28 & 0 & 4 & 32 & 2 & 11 & 0 & 0 & 13 & 75 \\
\hline \multicolumn{17}{|l|}{ 蟾眼蝶属 Triphysa } \\
\hline 蟾眼蝶 T. phryne & 0 & 1 & 0 & 0 & 1 & 8 & 0 & 0 & 0 & 8 & 6 & 2 & 0 & 0 & 8 & 17 \\
\hline \multicolumn{17}{|l|}{ 黛眼蝶属 Lethe } \\
\hline 黑带黛眼蝶 L. nigrifascia & 7 & 3 & 0 & 0 & 10 & 0 & 83 & 0 & 13 & 96 & 1 & 81 & 1 & 0 & 83 & 189 \\
\hline 苔娜黛眼蝶 L. diana & 4 & 0 & 0 & 0 & 4 & 0 & 6 & 1 & 1 & 8 & 0 & 0 & 0 & 0 & 0 & 12 \\
\hline 云南黛眼蝶 L.yunnana & 0 & 8 & 0 & 0 & 8 & 0 & 7 & 5 & 0 & 12 & 0 & 8 & 0 & 0 & 8 & 28 \\
\hline \multicolumn{17}{|l|}{ 红眼蝶属 Erebia } \\
\hline 红眼蝶 E. alcmena & 1 & 1 & 0 & 0 & 2 & 0 & 223 & 2 & 0 & 225 & 17 & 187 & 1 & 0 & 205 & 432 \\
\hline \multicolumn{17}{|l|}{ 荫眼蝶属 Neope } \\
\hline 黄斑荫眼蝶 N. pulaha & 0 & 112 & 18 & 5 & 135 & 0 & 47 & 11 & 14 & 72 & 0 & 21 & 0 & 36 & 57 & 264 \\
\hline \multicolumn{17}{|l|}{ 链眼蝶属 Lopinga } \\
\hline 黄环链眼蝶 L. achine & 0 & 179 & 0 & 1 & 180 & 4 & 91 & 4 & 7 & 106 & 0 & 12 & 1 & 0 & 13 & 299 \\
\hline \multicolumn{17}{|l|}{ 云眼蝶属 Hyponephele } \\
\hline 居间云眼蝶 H. interposita & 0 & 59 & 4 & 4 & 67 & 4 & 5 & 0 & 0 & 9 & 0 & 2 & 0 & 0 & 2 & 78 \\
\hline 西方云眼蝶 H. dysdora & 0 & 12 & 1 & 1 & 14 & 2 & 8 & 0 & 0 & 10 & 0 & 1 & 0 & 0 & 1 & 25 \\
\hline \multicolumn{17}{|l|}{ 蒰眼蝶属 Ypthima } \\
\hline 翟眼蝶 Y. balda & 8 & 121 & 6 & 4 & 139 & 2 & 1 & 0 & 0 & 3 & 0 & 6 & 0 & 0 & 6 & 148 \\
\hline 乱云嚾眼蝶 Y. megalomma & 0 & 6 & 0 & 0 & 6 & 0 & 14 & 1 & 1 & 16 & 1 & 2 & 0 & 0 & 3 & 25 \\
\hline \multicolumn{17}{|l|}{ 仁眼蝶属 Eumenis } \\
\hline 仁眼蝶 E. autonoe & 1 & 21 & 0 & 0 & 22 & 5 & 1 & 0 & 0 & 6 & 0 & 2 & 0 & 0 & 2 & 30 \\
\hline \multicolumn{17}{|l|}{ 蛇眼蝶属 Minois } \\
\hline 蛇眼蝶 M. dryas & 10 & 13 & 0 & 0 & 23 & 17 & 9 & 0 & 1 & 27 & 57 & 23 & 0 & 0 & 80 & 130 \\
\hline \multicolumn{17}{|l|}{ 亚洲白眼蝶属 Melanargia } \\
\hline 亚洲白眼蝶 M. asiatica & 1 & 12 & 1 & 0 & 14 & 34 & 339 & 1 & 13 & 387 & 66 & 153 & 6 & 11 & 236 & 637 \\
\hline 个体数合计 Total individuals & 135 & 1,364 & 7 & 34 & 1,605 & 146 & 1,396 & 42 & 85 & 1,669 & 190 & 806 & 23 & 70 & 1,089 & 4,363 \\
\hline 种数合计 Total species & 11 & 18 & 8 & 8 & & 11 & 18 & 9 & 10 & & 9 & 18 & 7 & 5 & & \\
\hline
\end{tabular}

$\mathrm{AV}$ : 人工植被; $\mathrm{CB}$ : 针阔混交林; $\mathrm{SH}$ : 灌木林; $\mathrm{BF}$ : 阔叶林

$\mathrm{AV}$, Artificial vegetation; $\mathrm{CB}$, Coniferous and broad-leaved mixed forest; SH, Shrub; BF, Broad-leaved forest

蝶 (Hyponephel edysdora) 的个体数分别占个体总数 的 1.05\%-8.39\%, 为保护区常见种; 蟾眼蝶 (Triphysa phryne) 个体数量最少, 仅占总个体数的 $0.39 \%$, 为保护区的稀有种。

\subsection{2 不同生境眼蝶物种分布}

从表2可以看出, 不同生境眼蝶群落组成不同, 不同年份眼蝶群落组成也不同。灌木林、阔叶林 2016-2018年的优势种均为阿芬眼蝶; 人工植被 
2016年的优势种为油庆珍眼蝶，2017年为爱珍眼蝶， 2018年为亚洲白眼蝶; 针阔混交林2016年的优势种 为阿芬眼蝶和油庆珍眼蝶, 2017年为阿芬眼蝶、亚 洲白眼蝶、爱珍眼蝶、红眼蝶, 2018年为爱珍眼蝶、 亚洲白眼蝶、红眼蝶。

从物种分布来看, 阿芬眼蝶、爱珍眼蝶、亚洲 白眼蝶、油庆珍眼蝶、黑带黛眼蝶、苔娜黛眼蝶等 均分布在 4 类以上生境中, 其中, 阿芬眼蝶在针阔 混交林生境中分布最多, 而蟾眼蝶、云南黛眼蝶只 分布在人工植被与针阔混交林中。4种生境类型中 眼蝶分布个体数量大小依次为针阔混交林 > 人工 植被 $>$ 阔叶林 $>$ 灌木林。

从个体数量变化来看, 2016-2018年, 仅人工植 被眼蝶个体数量增加, 其他生境眼蝶个体数量逐年 减少。

\section{2 不同生境眼蝶群落多样性}

2016-2018 年， 4 种生境类型中眼蝶群落 Shannon-Wiener多样性指数和Margalef丰富度指数
从大到小依次为针阔混交林 $>$ 人工植被 $>$ 灌木 林 > 阔叶林; Simpson优势度指数从大到小依次为 灌木林 > 阔叶林 > 人工植被 > 针阔混交林; Pielou均匀度指数从大到小依次为灌木林 $>$ 阔叶 林 $>$ 人工植被 $>$ 针阔混交林(图2)。

总体来看, 针阔混交林眼蝶群落物种数、个体 数、多样性指数和物种丰富度指数最高, 优势度指 数较低, 表明针阔混交林的植物群落相对稳定和复 杂，适合眼蝶生存。人工植被眼蝶群落多样性指数 相对较高, 优势度指数相对较低, 均匀度指数与丰 富度指数居中; 阔叶林眼蝶群落优势度相对较高, 但物种丰富度、多样性较低, 具有明显的优势种群, 群落结构相对稳定。灌木林眼蝶群落优势度最低, 均匀度最高, 多样性指数较高, 物种丰富度次低, 说明灌木林中眼蝶物种相对丰富, 群落结构稳定, 但优势物种不明显。

\section{3 不同生境眼蝶物种间的相似性}

人工植被与针阔混交林的眼蝶群落相似性系
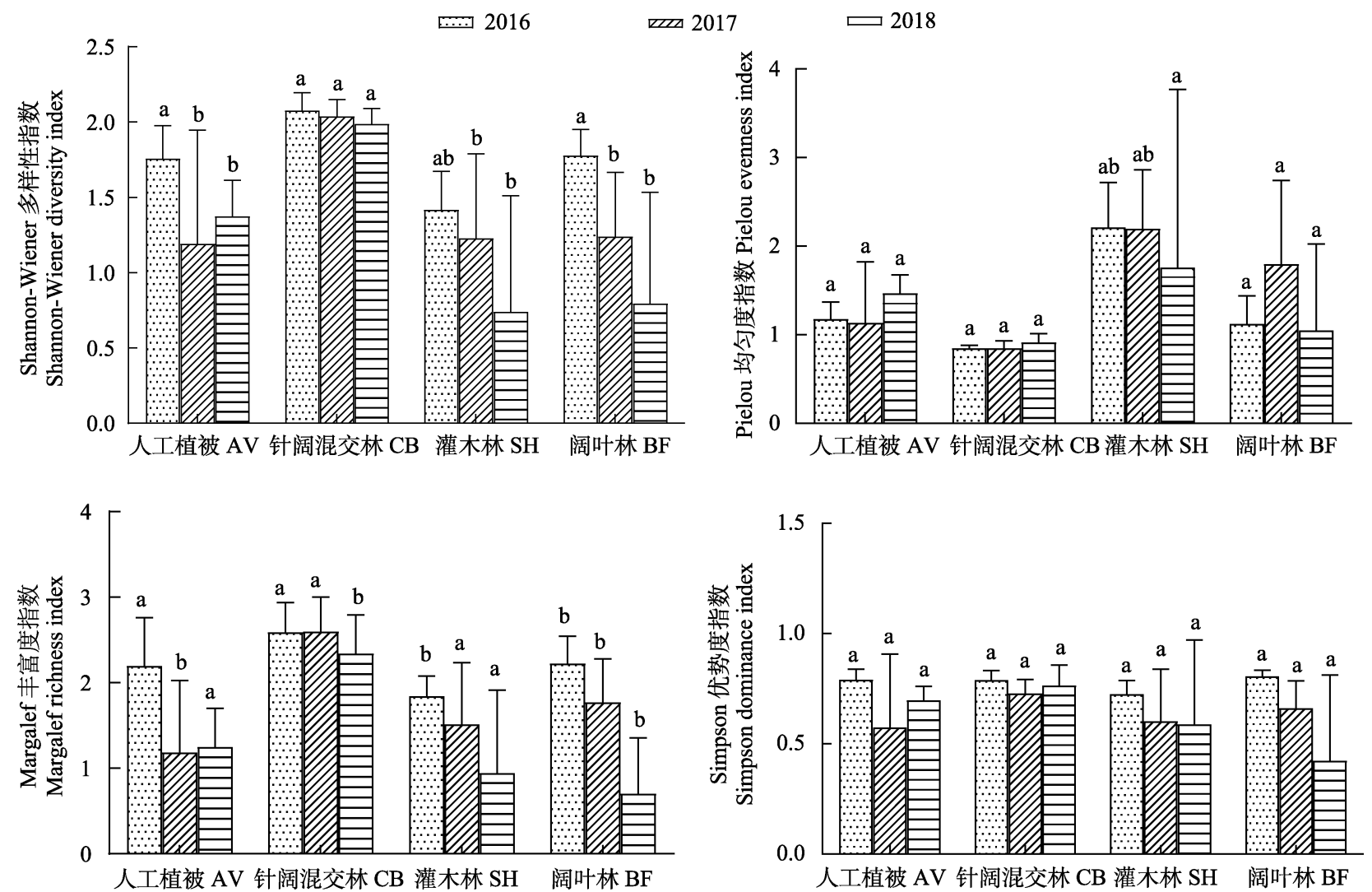

图2 2016-2018年六盘山国家级自然保护区不同生境眼蝶群落多样性指数。同一生境中不同字母表示差异显著 $(P<0.05)$ 。

Fig. 2 Diversity indices of Satyrinae community in different habitat types of the Liupanshan National Nature Reserve from 2016 to 2018. Different lowercase letters in the same habitat indicate a significant difference $(P<0.05)$. AV, Artificial vegetation; CB, Coniferous and broad-leaved mixed forest; SH, Shrub; BF, Broad-leaved forest. 
数在 0.5-0.75之间, 为中等相似, 其余的在 0.250.50 之间, 为中等不相似。针阔混交林与灌木林、 阔叶林的相似性系数在0.5-0.75之间，为中等相似。 其中人工植被和灌木林的相似性系数最低, 仅为 0.25 (表3)。

\section{4 眼蝶群落季节性变化}

2016-2018年，5-9月眼蝶个体数量均呈现先上 升后下降的趋势(图3A)。2016年, 眼蝶数为 1,605 只, 8月最多, 数量达1,005只; 5 月最低, 仅1只; 2017年, 眼蝶数为 1,669 只, 8 月为发生高峰期, 数量达 1,164 只; 9月最低, 仅3只; 2018年, 眼蝶数为1,089只, 7月 为发生高峰期, 数量为 959 只; 9 月为 0 只。眼蝶个体 总数呈逐年下降趋势, 发生高峰期也随之变化。 2018年极端天气与暴雨事件相对较多, 气温相对较 低, 可能是导致眼蝶物种个体高峰期出现在7月、9 月未观测到眼蝶的原因。

由图3B可以看出, 2016-2018年眼蝶种类数量 的高峰出现在7月, 2016年眼蝶物种数最高, 达14种, 5 月的种类最少, 仅 1 种。眼蝶群落的多样性指数和 物种丰富度高峰出现在 7 月, 此季节多数眼蝶寄主
植物生长较为茂盛, 温湿度适宜, 眼蝶种类逐渐增 多(图4)。

\section{4 讨论}

\section{1 眼蝶群落多样性的影响因素}

蝴蝶类群的分布与生境密切相关, 环境变化尤 其是土地利用变化和气候的变化会直接影响蝴蝶 的分布。研究发现, 全球变暖可改变蝴蝶的分布格 局(Pamesan et al, 1999; 陈洁君等, 2004)。本文中不 同生境眼蝶群落多样性存在差异，各生境的生态环 境质量及植物群落的差异是导致蝶类群落结构差 别的主要因素。针阔混交林物种丰富, 无人为干扰, 较适合于眼蝶以及其他蝶类的生存与繁衍。人工植 被中栽植马铃薯、杨树、草坪草, 增加了植物多样 性, 人为干扰较弱, 眼蝶种类与数量呈上升趋势, 说明植物多样性增加有助于眼蝶多样性的提高, 这 与Mahata等(2019)在印度农林植被对蝴蝶多样性研 究中的结论一致，与河西走廊、天津八仙山等地或 保护区的蝴蝶分布变化大体一致(倪永清等，2005; 张如力等, 2005), 农林植被不仅能提高蝴蝶的生物

表3 不同生境眼蝶群落共有种数 (对角线上)及相似性系数 (对角线下)

Table 3 Number of the shared species (above diagonal) and similarity coefficient (below diagonal) between habitat types

\begin{tabular}{|c|c|c|c|c|}
\hline $\begin{array}{l}\text { 生境类型 } \\
\text { Habitat type }\end{array}$ & $\begin{array}{l}\text { 人工植被 } \\
\text { Artificial vegetation }\end{array}$ & $\begin{array}{l}\text { 针阔混交林 } \\
\text { Coniferous and broad-leaved mixed forest }\end{array}$ & $\begin{array}{l}\text { 灌木林 } \\
\text { Shrub }\end{array}$ & $\begin{array}{l}\text { 阔叶林 } \\
\text { Broad-leaved forest }\end{array}$ \\
\hline 人工植被 Artificial vegetation & & 10 & 4 & 5 \\
\hline $\begin{array}{l}\text { 针阔混交林 Coniferous and broad-leaved } \\
\text { mixed forest }\end{array}$ & 0.5263 & & 9 & 10 \\
\hline 灌木林 Shrub & 0.2500 & 0.5000 & & 7 \\
\hline 阔叶林 Broad-leaved forest & 0.3125 & 0.5556 & 0.5833 & \\
\hline
\end{tabular}
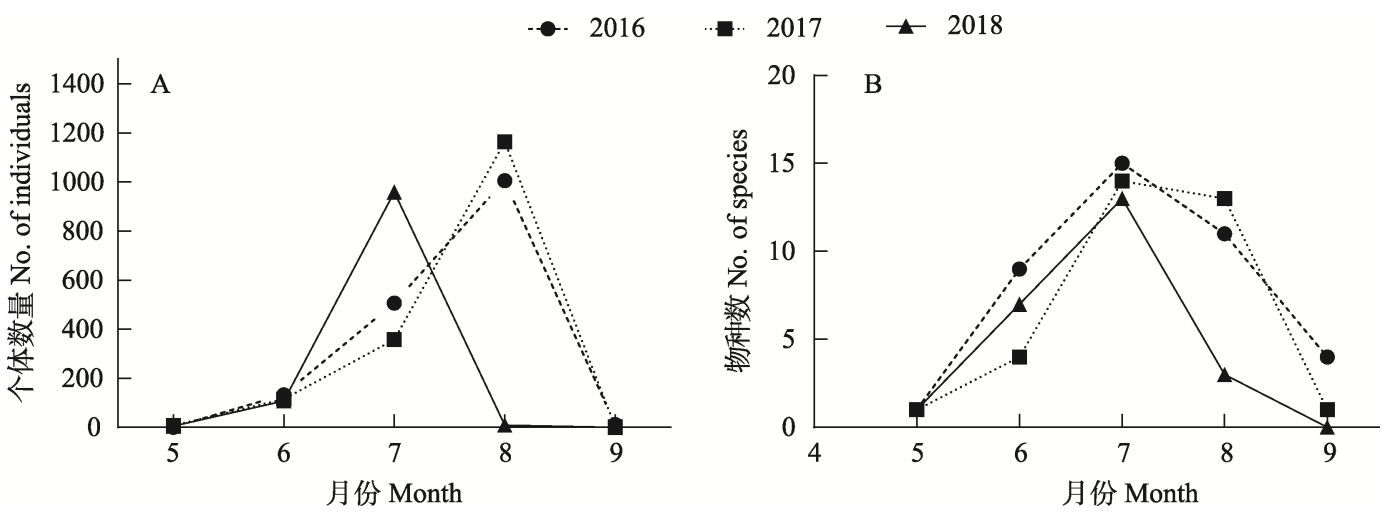

图32016-2018年六盘山国家级自然保护区眼蝶个体数量(A)和物种数(B)的时间动态

Fig. 3 Temporal dynamics of the number of individuals (A) and species (B) of Satyrinae in the Liupanshan National Nature Reserve from 2016 to 2018 

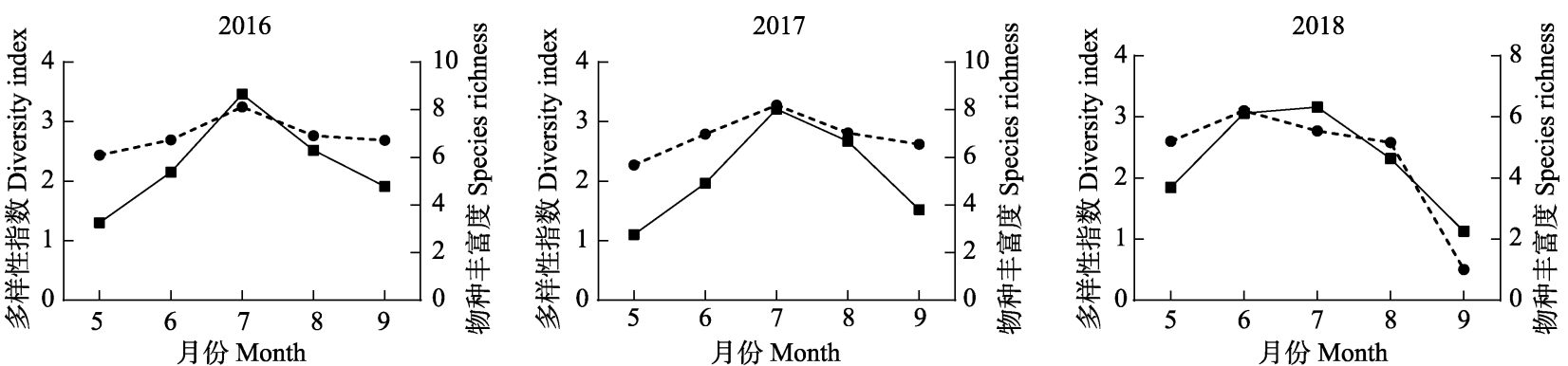

物种丰富度 Species richness -๑．多样性指数 Diversity index

图4 六盘山国家级自然保护区眼蝶群落多样性指数和物种丰富度指数的时间动态

Fig. 4 Temporal dynamics of diversity index and richness of Satyrinae butterfly in the Liupanshan National Nature Reserve from 2016 to 2018

多样性, 而且对蝴蝶保护也起着积极的作用。阔叶 林生境位于旅游中心地带, 监测样线所处沟道相对 狭窄, 且游客干扰活动较强, 眼蝶种类与数量较少, 这可能与人为干扰程度对眼蝶生长发育的影响有 关。4种生境中表现出的干扰活动, 符合“中度干扰” 理论, 适当的干扰有利于昆虫物种的繁衍, 在一定 程度上可提高生物多样性, 而超过 $30 \%$ 干扰强度才 能导致蝴蝶生物多样性下降甚至物种的消失 (Brown, 1997)。

\section{2 眼蝶群落的影响因素}

六盘山保护区拥有我国西北地区重要的森林 生态系统, 其自然生境优越, 植物区系多样, 年降 水量丰沛, 孕育着丰富的动植物资源, 其特殊的生 境也给蝶类的生存与繁衍提供了良好的场所。本研 究通过3年对六盘山保护区蝴蝶资源的调查, 发现 六盘山蝶类资源相对丰富, 仅眼蝶亚科就有 13 属 19 种。但在2016-2018年, 保护区眼蝶个体数量急剧下 降, 特别是 2018 年, 眼蝶数量较前两年减少 $25 \%$ 。 5-9月的调查表明, 眼蝶个体数呈现先上升后下降 的趋势。眼蝶种类数量的高峰出现在7月, 个体数量 的高峰主要出现在 8 月, 说明眼蝶的发生与寄主植 物有着密切的相关性。另外, 环境的变化对眼蝶的 发生也有着重大的影响, 蝴蝶对温度、光照、湿度 等环境因素十分敏感, 由于蝴蝶体温调节主要依赖 外界气温, 故气温过高或过低都会影响蝴蝶活动活 跃程度, 从而影响蝴蝶的飞行能力(Bonebrake et al, 2010; Forister et al, 2010; 赵彩云等, 2010; Advani et al, 2019)。2018年极端天气事件较多, 极端天气通过 气候的平均变化和极端气候事件对蝶类产生影响, 从而对种群造成威胁(房丽君和关建玲, 2010), 这也
是造成眼蝶物种与个体数量减少的因素之一。 如何在目前保护区的发展和建设基础上，进一 步监测蝴蝶对气候变化的响应, 建立评价生态系统 健康、恢复与重建状况的指标体系, 有效地保护自 然保护区蝶类资源是迫切需要开展的研究工作。

\section{参考文献}

Acharya BK, Vijayan L (2015) Butterfly diversity along the elevation gradient of Eastern Himalaya. Ecological Research, 30, 909-919.

Advani NK, Parmesan C, Singer MC (2019) Takeoff temperatures in Melitaea cinxia butterflies from latitudinal and elevational range limits: A potential adaptation to solar irradiance. Ecological Entomology, 44, 389-396.

Allan E, Manning P, Alt F, Binkenstein J, Blaser S, Bluthgen N, Bohm S, Grassein F, Holzel N, Klaus VH, Kleinebecker T, Morris EK, Oelmann Y, Prati D, Renner SC, Rillig MC, Schaefer M, Schloter M, Schmitt B, Schoning I, Schrumpf M, Solly E, Sorkau E, Steckel J, Steffen-Dewenter I, Stempfhuber B, Tschapka M, Weiner CN, Weisser WW, Werner M, Westphal C, Wilcke W, Fischer M (2015) Land use intensification alters ecosystem multifunctionality via loss of biodiversity and changes to functional composition. Ecological Letters, 18, 834-843.

Bonebrake TC, Ponisio LC, Boggs CL, Ehrlich PR (2010) More than just indicators: A review of tropical butterfly ecology and conservation. Biological Conservation, 143, 1831-1841.

Brown KS (1997) Diversity, disturbance, and sustainable use of Neotropical forests: Insects as indicators for conservation monitoring. Journal of Insect Conservation, 1, 25-42.

Chen JJ, Wang YF, Lei GC, Wang RJ, Xu RM (2004) Impact of habitat quality on metapopulation structure and distribution of two melitaeine butterfly species. Acta Entomologica Sinica, 47, 59-66. (in Chinese with English abstract) [陈洁君, 王义飞, 雷光春, 王戎疆, 徐汝梅 (2004) 栖息地质量对两种网蛱蝶集合种群结构和分布的 
影响. 昆虫学报, 47, 59-66.]

Chen ZN, Zeng Y (2001) The butterfly diversity of different habitat types in Qilian, Qinghai Province. Biodiversity Science, 9, 109-114. (in Chinese with English abstract) [陈 振宁, 曾阳 (2001) 青海祁连地区不同生境类型蝶类多 样性研究. 生物多样性, 9, 109-114.]

Chou I (1994) Monographia Rhopalocerorum Sinensium. Henan Science and Technology Publishing House, Zhengzhou. (in Chinese) [周尧 (1994) 中国蝶类志. 河南 科学技术出版社, 郑州.]

Chou I (1998) Colored Atlas of Chinese Butterflies. Henan Science and Technology Publishing House, Zhengzhou. (in Chinese) [周尧 (1998) 中国蝴蝶原色图鉴. 河南科学技 术出版社, 郑州.]

Chou I (1999) Classification and Identification of Chinese Butterflies. Henan Science and Technology Publishing House, Zhengzhou. (in Chinese) [周尧 (1999) 中国蝴蝶分类 与鉴定. 河南科学技术出版社, 郑州.]

Chou I, Yuan XQ, Zhang CS (2001) A new record species of butterflies from China (Lepidoptera, Satyrinae). Entomotaxonomia, 23, 201-216. (in Chinese with English abstract) [周尧, 袁向群, 张传诗 (2001) 中国蝴蝶新种, 新亚种及新记录种 $(\mathrm{V})$ (鳞翅目: 眼蝶科). 昆虫分类学报, 23, 201-216.]

Crone EE, Pelton EM, Brown LM, Thomas CC, Schultz CB (2019) Why are monarch butterflies declining in the West? Understanding the importance of multiple correlated drivers. Ecological Applications, 29, e01975.

Dan ZC, Bao M, Ma CX, Li LL, Hao HW, Cheng F, Cai XZM, Chen ZN (2018) Community structure and butterfly diversity in different habitat types in the Qinghai Yushu Plateau. Acta Ecologica Sinica, 38, 7557-7564. (in Chinese with English abstract) [旦智措, 鲍敏, 马存新, 李雷雷, 郝 会文, 成帆, 才项卓玛, 陈振宁 (2018) 青海玉树高原不 同生境类型蝶类群落结构与多样性. 生态学报, 38, 7557-7564.]

Deng HL, Ma Q, Li AM (2012) The establishment of the indication on environmental health of butterfly and of the environmental monitoring evaluation system in Chongqing. Acta Ecologica Sinica, 32, 5208-5218. (in Chinese with English abstract) [邓合黎, 马琦, 李爱民 (2012) 重庆市 蝴蝶多样性环境健康指示作用和环境监测评价体系构建. 生态学报, 32, 5208-5218.]

Ekroos J, Kuussaai M, Tianien J, Heliöläb J, Seimola T, Heleniusd J (2013) Correlations in species richness between taxa depend on habitat, scale and landscape context. Ecological Indicators, 34, 528-535.

Fang LJ, Guan JL (2010) Progress in the studies of butterflies in responding to global climate change. Journal of Environmental Entomology, 32, 399-406. (in Chinese with English abstract) [房丽君, 关建玲 (2010) 蝴蝶对全球气候变化 的响应及其研究进展. 环境昆虫学报, 32, 399-406.]

Fang LJ, Zhang YL (2010) Community structure and diversity of butterfly in Liupanshan National Nature Reserve of Ningxia, China. Chinese Journal of Applied Ecology, 21, 973-978. (in Chinese with English abstract) [房丽君, 张雅 林 (2010) 宁夏六盘山国家自然保护区蝶类群落结构和 多样性. 应用生态学报, 21, 973-978.]

Filz KJ, Wiemers M, Herrig A, Weitzel M, Schmitt T (2013) A question of adaptability: Climate and habitat change lower trait diversity in butterfly communities in south-western Germany. European Journal of Entomology, 110, 633-642.

Forister ML, McCall AC, Sanders NJ, Fordyce JA, Thorne JH, O’Brien J, Waetjen DP, Shapiro AM (2010) Compounded effects of climate change and habitat alteration shift patterns of butterfly diversity. Proceedings of the National Academy of Sciences, USA, 107, 2088-2092.

Franzen M, Schrader J, Sjoberg G (2017) Butterfly diversity and seasonality of Ta Phin Mountain area (N. Vietnam, Lao Cai, province). Journal of Insect Conservation, 21, 465-475.

Hu HL, Song YY, Wang XJ (2014) A new synonym of Neope contrasta (Lepidoptera, Nymphalidae). Journal of Mountain Agriculture and Biology, 33, 53-54. (in Chinese with English abstract) [胡华林, 宋育英, 汪学俭 (2014) 桐木 荫眼蝶一新异名 (鳞翅目: 蛱蝶科). 山地农业生物学报, 33, 53-54.]

Hu JG, Li Y, Zhai PH (2016) A new record species of genus Erebia from China (Lepidoptera: Nymphalidae: Satyrinae). Journal of Northeast Forestry University, 44, 104-106. (in Chinese with English abstract) [胡金贵, 李晔, 翟鹏辉 (2016) 中国红眼蝶属1新记录种记述(鳞翅目: 蛱蝶科: 眼蝶亚科). 东北林业大学学报, 44, 104-106.]

Jaccard P (1900) Contribution au probleme de l'immigration post-glaciaire de la flora alpine. Bulletin de la Société Vaudoise des Sciences Naturelles, 36, 732-739.

Ma FZ, Xu HG, Chen MM, Tong WJ, Wang CB, Cai L (2018) Progress in construction of China butterfly diversity observation network (China BON-Butterflies). Journal of Ecology and Rural Environment, 34, 27-36. (in Chinese with English abstract) [马方舟, 徐海根, 陈萌萌, 童文君, 王晨涁, 蔡蕾 (2018) 全国蝴蝶多样性观测网络(China BON-Butterflies) 建设进展. 生态与农村环境学报, 34, 27-36.]

Ma KP, Liu YM (1994) Measurement of biotic community diversity. I. $\alpha$ diversity (Part 2). Chinese Biodiversity, 2, 231-239. (in Chinese) [马克平, 刘玉明 (1994) 生物群落 多样性的测度方法. I. $\alpha$ 多样性的测度方法(下). 生物多样 性, 2, 231-239.]

Mahata A, Samal KT, Palita SK (2019) Butterfly diversity in agroforestry plantations of Eastern Ghats of southern Odisha, India. Agroforestry Systems, 93, 1423-1438.

Margalef R (1967) Some concepts relative to the organization of plankton. Oceanography Marine Biology: An Annual Review, 5, 257-289.

Editorial Committee of Nature Science Survey of Liupan Mountains (1988) Nature Science Survey Report of Liupan 
Mountain. Ningxia People’s Press, Yinchuan. (in Chinese) [六盘山自然保护区科学考察编辑委员会 (1988) 六盘山 自然保护区科学考察报告. 宁夏人民出版社, 银川.]

Ni YQ, Li XM, Ni ZY, Xie ZP, Zhang Y, Zhu J (2005) Diversity of butterflies community in different habitat types in the northern mountains region of Hexi Corridor. Acta Prataculturae Sinica, 14, 53-57. (in Chinese with English abstract) [倪永清, 李晓明, 倪自银, 谢宗平, 张勇, 朱杰 (2005) 河西走廊北山山地不同生境蝶类群落多样性研 究. 草业学报, 14, 53-57.]

Pamesan C, Ryrholm N, Stefanescu C, Hill JK, Thomas CD, Descimon H, Huntley B, Kaila L, Kullberg J, Tammaru T, Tennent WJ, Thomas JA, Warren M (1999) Polew and shifts in geographical ranges of butterfly species associated with regional warming. Nature, 399, 579-583.

Peña C, Nylin S, Wahlberg N (2011) The radiation of Satyrini butterflies (Nymphalidae: Satyrinae): A challenge for phylogenetic methods. Zoological Journal of the Linnean Society, 161, 64-87.

Pielou EC (1975) Ecological Diversity. John Wiley \& Sons, New Jersey.

Ren GD (2010) Fauna of Invertebrata from Liupan Mountain. Hebei University Publishing House, Baoding. (in Chinese) [任国栋 (2010) 六盘山无脊椎动物. 河北大学出版社, 保定.]

Riva F, Acorn JH, Nielsen SE (2018) Localized disturbances from oil sands developments increase butterfly diversity and abundance in Alberta's boreal forests. Biological Conservation, 217, 173-180.

Shou JX (2006) Systematic Butterfly Names of the World. Shaanxi Science and Technology Press, Xi'an. (in Chinese) [寿建新 (2006) 世界蝴蝶分类名录. 陕西科学技术出版 社, 西安.]

Whittaker RH (1972) Evolution and measurement of species diversity. Taxon, 21, 213-251.

Yang P, Liu WP, Deng HL (2002) Study on the relationship between satyrids in Chongqing and its habitat. Journal of Southwest Agricultural University, 24, 413-417, 453. (in Chinese with English abstract) [杨萍, 刘文萍, 邓合黎 (2002) 重庆市眼蝶与生态环境关系的研究. 西南农业大 学学报, 24, 413-417, 453.]

Zhai Q, Zhang YL (2011) A new species and a new subspecies of Lethe hubner (Lepidoptera, Nymphalidae, Satyrinae) from China. Acta Zootaxonomica Sinica, 36, 45-48.

Zhang RL, Zhang RQ, Xiao YF (2005) The vertical distribution and biodiversity of Parnassius at Si Da Long forest pastoral areas in Qilian Mountains (northern slope). Pratacultural Sinica, 22, 9-13. (in Chinese with English abstract) [张如 力, 张如清, 肖云峰 (2005) 绢蝶在祁连山(北坡)寺大隆 林牧区的垂直分布及物种多样性. 草业科学, 22, 9-13.]

Zhang X, Hu HY, Lü ZZ (2013) Butterfly diversity and vertical distribution in eastern Tianshan Mountain in Xinjiang. Acta Ecologica Sinica, 33, 5329-5338. (in Chinese with English abstract) [张金金, 胡红英, 吕昭智 (2013) 新疆东部天山蝶 类多样性及其垂直分布. 生态学报, 33, 5329-5338.]

Zhao CY, Li JS, Luo JW, Xiao NW, Luo ZL (2010) A review on responses of butterflies to global climate change. Acta Ecologica Sinica, 30, 1050-1057. (in Chinese with English abstract) [赵彩云, 李俊生, 罗建武, 肖能文, 罗遵兰 (2010) 蝴蝶对全球气候变化响应的研究综述. 生态学报, 30, 1050-1057.]

Zhou GY, Gu MB, Gong YN, Wang SK, Wu ZM, Xie GG (2016) Diversity and fauna of butterflies in Nanling National Nature Reserve. Journal of Environmental Entomology, 38, 971-978. (in Chinese with English abstract) [周光益, 顾茂 涁, 龚粤宁, 王胜坤, 吴仲民, 谢国光 (2016) 南岭国家 级自然保护区蝴蝶多样性与区系研究. 环境昆虫学报, 38, 971-978.]

(责任编委: 黄晓磊 责任编辑: 问文杰) 